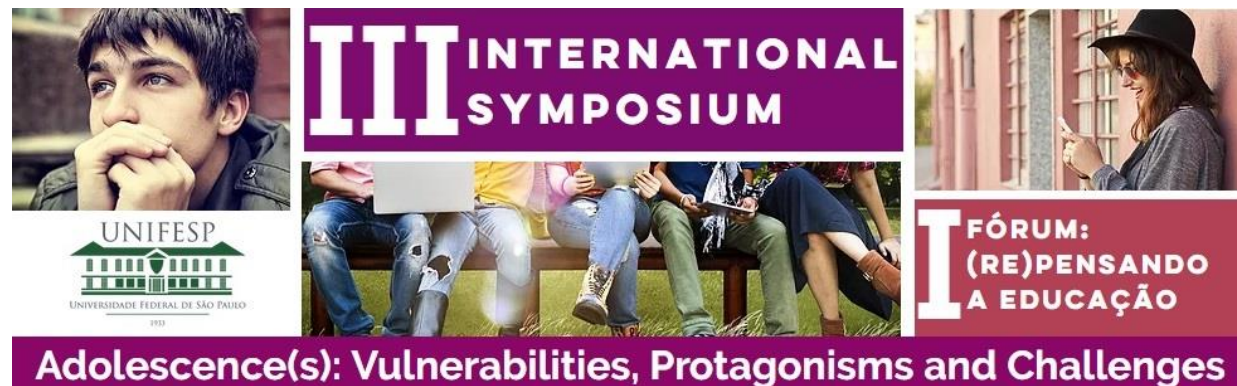

PROMOTION OF MENTAL HEALTH IN TEACHERS OF ELEMENTARY SCHOOL LINTERVENTION IN SCHOOLS WITH THE FRIENDS

\title{
PROMOÇÃO DE SAÚDE MENTAL EM PROFESSORES DO ENSINO FUNDAMENTAL 1 - INTERVENÇÃO EM ESCOLAS COM O MÉTODO FRIENDS
}

Larissa Zeggio' ${ }^{\text {; Chintia Catellan }}{ }^{2}$ Keity Lioi ${ }^{3}$ Tatiane Sanches ${ }^{4}$

1. Larissa Zeggio - (IBIES)

E-mail: larissazeggio@gmail.com

2. Chintia Catellan - Psicóloga Clínica

E-mail: cinthia.catellan@gmail.com

3. Keity Lioi

E-mail: keity@maplebear.com.br

4. Tatiane Sanches - Graduanda $8^{\circ}$ Semestre em psicologia UNG

E-mail: tatiane.besenbruch@gmail.com

* Trabalho de conclusão de curso de Facilitadoras do Método Friends - Nivel 1V - Escola Maple Bear - São Bernardo do Campo/ SP - Março 2017 (IBIES)

\section{Como citar:}

ZEGGIO, Larissa et al. Promotion of mental health in teachers of elementary school l-intervention in schools with the friends. In: INTERNATIONAL SYMPOSIUM ADOLESCENCE(S) \& FÓRUM (RE)PENSANDO A EDUCAÇÃO, 3, 2017, São Paulo. Anais... São Paulo: Unifesp, 2017. p. 33-34.

DOI: http://dx.doi.org/10.22388/2525-5894.2017.015

Está bem descrito na literatura que os professores são uma das classes profissionais que mais apresenta problemas de saúde emocional em nosso país, sobretudo ansiedade, depressão e burnout, com consequências como afastamentos médicos, redução da produtividade e problemas na relação professor-aluno que interferem também com a aprendizagem dos estudantes. Portanto, intervenções que visem melhorar a saúde emocional dos professores devem ser incentivadas. O Método FRIENDS é um protocolo internacional de intervenção em saúde mental, baseado em evidências científicas, utilizado com o objetivo de desenvolver e aprimorar habilidades socioemocionais, promover resiliência e prevenir ansiedade e depressão em crianças, jovens e adultos. Está baseado em técnicas da terapia cognitivo-comportamental, da psicologia positiva e de evidências da neurociência nas atividades propostas. Apesar das 
evidências internacionais, estudos brasileiros com esse protocolo são escassos e inexistem no público de professores.

Nesse sentido, o objetivo do presente trabalho foi avaliar os efeitos do Método FRIENDS Programa VIDA Resiliência em Adultos na saúde emocional da equipe de educadores de uma escola privada de educação básica.

Para tanto, a aplicação do Programa foi realizada, em grupo, com 13 participantes (duas coordenadoras e onze professoras da educação infantil e ensino fundamental I) de uma escola privada de São Bernardo do Campo (SP). Após palestra-convite e adesão de 100\% da equipe, o protocolo foi aplicado em sete encontros (3 horas cada), cinco semanais e dois de reforço 30 e 60 dias após o quinto encontro. Para avaliação dos efeitos do Programa foram utilizados três instrumentos [PANAS - Escala de Afetos Positivos e Negativos; Escala de Auto-Estima de Rosemberg; e Escala de Esperança Cognitiva] em dois momentos: antes do $1^{\circ}$ encontro (basal) e após o $7^{\circ}$ encontro (avaliação de acompanhamento), além da avaliação qualitativa por meio de relatos dos participantes, que sinalizaram mudanças em seus hábitos de vida já no andamento do programa como por exemplo, o início da prática de atividades físicas e treino de relaxamento como parte da rotina com seus familiares e novos hábitos em sua vida profissional. A análise quantitativa demonstrou melhoras nos parâmetros avaliados. Embora mais estudos sejam necessários o presente trabalho sinaliza que intervenções como estas podem ser promissoras no contexto escolar e merecem atenção.

Palavras-chave: Promoção de Saúde Mental. Habilidades Socioemocionais. Educadores. 